\title{
Evolution and the Growth Process: Natural Selection of Entrepreneurial Traits*
}

\author{
Oded Galor ${ }^{\dagger}$ and \\ Brown University \\ Stelios Michalopoulos \\ Tufts University and the Institute for Advanced Study, Princeton
}

\begin{abstract}
This research suggests that a Darwinian evolution of entrepreneurial spirit played a significant role in the process of economic development and the dynamics of inequality within and across societies. The study argues that entrepreneurial spirit evolved non-monotonically in the course of human history. In early stages of development, risk-tolerant, growth promoting traits generated an evolutionary advantage and their increased representation accelerated the pace of technological progress and the process of economic development. In mature stages of development, however, risk-averse traits gained an evolutionary advantage, diminishing the growth potential of advanced economies and contributing to convergence in economic growth across countries.
\end{abstract}

\section{Keywords}

Risk Aversion; Growth; Technological Progress; Evolution; Natural Selection

\section{Introduction}

This research advances the hypothesis that a Darwinian evolution of entrepreneurial spirit played a significant role in the process of economic development and the time path of inequality within and across societies. The theory suggests that the prevalence of entrepreneurial traits evolved non-monotonically in the course of human history. In the early stages of development risk-tolerant, growth promoting traits generated an evolutionary advantage and their increased representation accelerated the pace of technological advancements, contributing significantly to the process of development and the transition from stagnation to growth. As economies matured, however, this evolutionary pattern was reversed. Risk-averse traits gained an evolutionary advantage, diminishing the growth potential of advanced economies and contributing to convergence in economic growth across countries. Historical variations in geographical, institutional and cultural factors

\footnotetext{
*The authors wish to thank an associate editor, 3 referees, Peter Howitt, Ashley Lester, Ross Levine, Miles Kimball, Yona Rubinstein and seminar participants at the Max Planck Institute, Warwick University, Athens University of Economics and Business, Crete Conference, the Minerva - DEGIT XI conference and AEA Meetings for helpful discussions and useful comments.

${ }^{\dagger}$ Corresponding author. Department of Economics, Brown University, 64 Waterman St., Providence, RI 02912, USA. Phone: +401 863-2117, Fax: +401 863 1970. Oded_Galor@brown.edu.

Stelios.Michalopoulos@tufts.edu
} 
which affected the pace of this evolutionary process and thus the prevalence of growthpromoting entrepreneurial traits across economies, contributed to contemporary differences in productivity and income per-capita across countries.

Unlike the commonly emphasized forces for economic convergence (i.e., higher returns to human capital, physical capital, and technological adoption, for laggard countries), the research proposes that a higher prevalence of growth-promoting entrepreneurial traits in developing economies contributed to economic convergence. Moreover, the predictions of the proposed theory provide further understanding of the path of income inequality within a society over time. The study suggests that as economies mature, inequality subsides due to higher representation of entrepreneurial traits among lower income individuals. This prediction is consistent with the class origin of entrepreneurs during the industrial revolution. The failure of the landed aristocracy to lead the innovative process of industrialization could be attributed to the low representation of growth promoting entrepreneurial traits within the landed gentry, and their prevalence among the middle and the lower classes.

The study develops an evolutionary growth theory that underlines the importance of the evolution of entrepreneurial spirit in the transition from stagnation to growth. It constructs an overlapping-generations economy that due to the forces of natural selection evolves endogenously from a Malthusian epoch into a state of sustained economic growth. The growth process is fueled by technological progress that is affected positively by the level of income per worker as well as by the prevalence of entrepreneurial traits in the economy. ${ }^{1}$

The theory rests upon two fundamental building blocks. First, technological change is affected positively by the frequency of risk-tolerant traits in the population. The intensity of entrepreneurial spirit affects the contemporaneous production choices and advances the technological frontier available to subsequent generations. ${ }^{2}$ The second central building block is the heritability of such traits across generations. Consistent with the supposition that entrepreneurial spirit is heritable, evidence described in section 1.2, suggests that the trait of "novelty seeking" has been subjected to a selection process in the recent past. More generally, evidence suggests that evolutionary processes in the composition of existing genetic traits may be rather rapid, and major evolutionary changes have occurred in the human population over the time period that is the focus of this study. ${ }^{3}$

\footnotetext{
${ }^{1}$ The theory is perfectly applicable to either social or genetic intergenerational transmission of entrepreneurial traits. Allowing preferences to be transmitted both via vertical and horizontal transmission processes might affect the speed of selection of entrepreneurial spirit in the process of development (Bisin and Verdier [4], Cavalli-Sforza et al. [8], and Boyd et al. [7]).

${ }^{2}$ The positive association between the frequency of the entrepreneurial individuals in the population and the rate of technological growth is well documented in the literature, and is at the foundation of the Schumpeterian viewpoint (e.g., Schumpeter [38], Aghion and Howitt [2]), where the role of entrepreneurs is instrumental in the process of innovations.

${ }^{3}$ Voight et al. [40] detected about 700 regions of the human genome where genes appear to have been reshaped by natural selection within the last 5,000 to 15,000 years. Moreover, a study by Mekel-Bobrov [31] reports that a variant of the gene ASPM (a specific regulator of brain size in the lineage leading to Homo sapiens) arose in humans merely about 5800 years ago and has since swept to high frequency under strong positive selection. Other notable evidence suggests that lactose tolerance was developed among Europeans and Near Easterners since the domestication of dairy animals in the course of the Neolithic revolution, whereas in regions that were exposed to dairy animals in later stages, a larger proportion of the adult population suffers from lactose intolerance. Furthermore, genetic immunity to malaria provided by the sickle cell trait is prevalent among descendents of Africans whose engagement in agriculture improved the breeding ground for mosquitoes and thereby raised the incidence of malaria, whereas this trait is absent among descendents of nearby populations that have not made the transition to agriculture (Livingstone [28], Wiesenfeld [45] and Durham [14]).
} 
Variations in entrepreneurial spirit among individuals are originated from differences in the degree of risk aversion with respect to consumption. In the proposed formulation they also reflect differences in the elasticity of substitution between consumption and fertility, capturing the sensitivity of individuals to changes in relative prices and thus arbitrage opportunities. ${ }^{4}$ Differences in the degree of risk aversion across individuals affect their reproductive success and are transmitted across generations, either genetically or culturally. In early stages of development risk aversion has an adverse effect on fertility and reproductive success, raising the frequency of risk-tolerant, growth promoting traits in the economy and stimulating the growth process. However, as economies mature, risk aversion has a beneficial effect on reproductive success, diminishing the growth potential of the economy.

The reversal in the evolutionary advantage of the risk-tolerant traits stems from the effect of the level of income on the relative cost of consumption and child rearing. As the economy progresses and income per capita increases, the opportunity cost of child rearing (indexed to the level of income per capita) increases relative to consumption. At sufficiently low levels of income the cost of children is lower relative to the cost of consumption. Risk-tolerant individuals, whose choices are more responsive to the relative prices than risk-averse individuals, optimally allocate more resources towards child rearing and the representation of their type increases in the population over time. As the economy develops and income per capita increases, the cost of raising children increases relative to the cost of consumption. Risk-tolerant individuals optimally allocate more resources towards consumption and less towards children and the prevalence of entrepreneurial spirit declines over time.

Interestingly, the forces of natural selection are critical for the escape from an epoch of stagnation. In their absence the economy may remain indefinitely in a Malthusian equilibrium. Namely, if entrepreneurial traits are not hereditary and the distribution of these traits remains unchanged over time, the level of income per worker may be stationary and fertility will be at replacement level. Technological advancement will be counterbalanced by an increase in population growth, whereas adverse technological shocks will be offset by population decline.

The predictions of the theory regarding the reversal in the evolutionary advantage of entrepreneurial, risk-tolerant individuals in more advanced stages of development could be examined based on the effect of the degree of risk aversion on fertility choices in contemporary developed and less developed economies. Existing evidence is consistent with the proposed hypothesis suggesting that risk tolerance is positively associated with the number of children in less developed economies and negatively in developed economies. ${ }^{5}$

\subsection{Related Literature}

The transition from stagnation to growth and the associated phenomenon of the great divergence have been the subject of intensive research in the growth literature in recent

\footnotetext{
${ }^{4}$ There is large literature in economics that has historically linked entrepreneurial propensity to personal traits. Hayek [23] and Kirzner [24], for example, have stressed the importance of entrepreneurs' responsiveness to incentives and changes in relative prices.

${ }^{5}$ See Finkelman and Finkelstein [15]; Miyata [32]; Dohmen et al. [13].
} 
years. ${ }^{6}$ It has been increasingly recognized that the understanding of the contemporary growth process would be fragile and incomplete unless growth theory could be based on proper micro-foundations that would reflect the various qualitative aspects of the growth process and their central driving forces. Moreover, it has become apparent that a comprehensive understanding of the hurdles faced by less developed economies in reaching a state of sustained economic growth would be futile unless the factors that prompted the transition of the currently developed economies into a state of sustained economic growth could be identified and their implications would be modified to account for the differences in the growth structure of less developed economies in an interdependent world.

The exploration of the interaction between human evolution and the process of economic development was pioneered by Galor and Moav [17]. ${ }^{7}$ They advance the hypothesis that during the Malthusian epoch, when the subsistence-consumption constraint affected the vast majority of the population, the forces of natural selection operated relentlessly and the survival of the fittest complemented the growth process, and contributed to the process of industrialization and the transition of the world economy from stagnation to growth. In particular, they argue that the Neolithic revolution and the subsequent epoch of Malthusian stagnation triggered a selection of traits of higher valuation for offspring quality, that played a significant role in the process of industrialization and the demographic transition. ${ }^{8}$. The proposed theory highlights an alternative channel via which the forces of natural selection may have contributed to the transition from stagnation to growth, underlying the selection of entrepreneurial traits in the process of development.

The implications of the proposed theory for the class origin of entrepreneurs during the Industrial Revolution are complementary to those of Doepke and Zilibotti [11, 12]. Their theory suggests that a new class of entrepreneurs rising from the middle classes, imbued with ethics emphasizing patience and savings, proved most capable of profiting from new economic opportunities, and eventually surpassed the pre-industrial elite. Similarly, the proposed theory suggests that the failure of the landed aristocracy to lead the innovative process of industrialization could be attributed to the effect of natural selection on the lower prevalence of entrepreneurial spirit among the landed gentry, and a higher prevalence among the middle and the lower classes. ${ }^{9}$

\footnotetext{
${ }^{6}$ See e.g., Galor and Weil [19, 20], Galor and Moav [18], Galor [16], Hansen and Prescott [21] and Lucas [29].

${ }^{7}$ Lagerlöf [27] examines the interaction between the evolution of body size and the process of development since the emergence of the Homo sapiens. Spolaore and Wacziarg [39] examine the effect of differences in human characteristics that are transmitted across generations on the diffusion of development across countries over the very long run. Other studies have abstracted from the reciprocal interaction between human evolution and the process of development and have focused on the effect of the economic environment on the evolution of human characteristics. Ofek [34] and Saint-Paul [37] examine the effect of the emergence of markets on the evolution of heterogeneity in the human population. Galor and Moav [18] study the effect of the Neolithic Revolution and the associated rise in population density on the evolution of life expectancy, and Borghans et al. [5] explore the effect of human cooperation on the evolution of Major Histocompatibility Complex (MHC).

${ }^{8}$ The evolution of preferences, in a given economic environment, has been explored in the economic literature, as surveyed by Weibull [41] and Bowles [6], and is explored more recently by Weibull and Salomonsson [42]. Welch and Bernardo [43] establish that overconfident entrepreneurs are evolutionarily optimal in an environment characterized by poor aggregation of information and herding behavior. Overconfident entrepreneurs provide a positive information externality to the group they belong to by revealing their own information. Palacios-Huerta and Santos [35] examine the effect of market incompleteness on the formation of risk aversion, demonstrating that if the formation of lower risk aversion is costly market completeness and greater risk aversion are complements. ${ }^{9}$ Moreover, the existence of primogeniture in preindustrial Europe limited social and income mobility between the landed gentry and the other classes (Bertocchi [3]), allowing the forces of natural selection to differentially affect the evolution of entrepreneurial spirit across classes, and leading to the observed variations in the involvement of the upper and the middle class in the Industrial Revolution.
} 


\subsection{Genetic Evidence About the Evolution of Novelty Seeking}

Evidence from twin studies strongly suggests that a substantial component of the observed variation in degrees of novelty seeking - a trait closely associated with the notion of entrepreneurial spirit - may be attributed to genetic variation (Rodgers et al. [36] and Kohler et al. [25]). ${ }^{10}$ In particular, the dopamine receptor D4 (D4DR) gene has been studied extensively in the biological literature as a potential candidate for moderating noveltyseeking behavior. Although the evidence is still inconclusive, a positive association between a certain polymorphism in the D4DR (the 7R allele) and novelty-seeking behavior is most widely documented. Furthermore, Ding et al. [10] studying a worldwide population sample, proposed that the $7 \mathrm{R}$ allele originated as a rare mutational event about 40,000 years ago that increased to high frequency in human populations by positive selection. To the extent that the $7 \mathrm{R}$ allele is associated with novelty-seeking behavior, these findings are consistent with the basic prediction of the model. At early stages of economic development risk-tolerant individuals have an evolutionary advantage, and the introduction of such traits in an environment characterized by very low income levels should have led to an appreciable increase in their representation in the population.

Moreover, complementary evidence suggests that entrepreneurial propensity is hereditary. White et al. [44] examine empirically how entrepreneurial activity is associated with testosterone levels. They find that higher testosterone levels are significantly associated with prior new venture start-up experience. Increased testosterone levels increase the probability of entrepreneurial activity both directly and indirectly via the propensity towards risk. This finding coupled with studies from endocrinology (Meikle et al. [30] and Harris et al.[22] ), which show that production of testosterone levels is heritable, further substantiate the hypothesis regarding a genetic heritability of entrepreneurial propensity. ${ }^{11}$

\section{The Basic Structure of the Model}

Consider an overlapping-generations economy in which economic activity extends over infinite discrete time. In every period the economy produces a single homogeneous good using land and labor as inputs in the production process. The supply of land is exogenous and fixed over time whereas the supply of labor is determined by the size of the population.

\subsection{Production of Final Output}

Production occurs according to a constant-returns-to-scale technology that is subject to endogenous technological progress. The aggregate output produced at time $t, Y_{t}$, is:

$$
Y_{t}=\left(A_{t} X\right)^{\alpha} L_{t}^{1-\alpha} ; \quad \alpha \in(0,1)
$$

\footnotetext{
${ }^{10}$ Cloninger [9] proposed four genetically homogeneous and independent dimensions of personality: novelty seeking, harm avoidance, reward dependence, and persistence that are hypothesized to be based on distinct neurochemical and genetic substrates. As elaborated by Kose [26], "Individuals exhibiting high novelty seeking are enthusiastic, curious, and are quick to engage with whatever is new and unfamiliar, which leads to exploration of potential rewards. Furthermore, they get excited about new ideas and activities easily thus they may be described as unconventional or innovative." Several studies have shown that a large component of the observed variation in these behavioral traits can be attributed to genetic differences.

${ }^{11}$ Nielsen et al. [33] find that within the group of genes that shows the strongest evidence for positive selection in humans there are also genes that are involved in spermatogenesis that directly influence testosterone levels.
} 
where $L_{t}$ is the labor employed in period $t, X$ is the land used in production in every period, $A_{t}$ is the average technological level in period $t$, and $A_{t} X$ is therefore the "effective resources" available during the period.

Suppose that there are no property rights over land. ${ }^{12}$ The return to land in every period is therefore zero and output per worker produced at time $t, y_{t}$, is given by:

$$
y_{t}=\left[\left(A_{t} X\right) / L_{t}\right]^{\alpha} \text {, }
$$

where $\left(A_{t} X\right) / L_{t}$ is the level of effective resources per worker in period $t$.

\subsection{Preferences and Constraints}

In every period $t$, a generation that consists of a continuum of individuals of mass $L_{t}$ joins the labor force. Each individual $i$ has a single parent. Members of generation $t$ (those who join the labor force in period $t$ ) live for two periods. In the first period of life (childhood), individual $i$ is economically idle. In the second period of life (parenthood) individual $i$ of generation $t$ is endowed with 1 unit of time. The individual works and generates income, $y_{t}^{i}$.

Every generation $t$ consists of two types of individuals, 1 and 2, distinguished by the degree of risk aversion with respect to consumption. Preferences are transmitted without alteration from generation to generation within a dynasty either genetically or culturally. The distribution of types within each period evolves over time due to the effect of natural selection on the reproductive success of each type.

The utility function of individual $i$ in period $t$ is defined over consumption, $c_{t}^{i}$, and children, $n_{t}^{i}$, in period $t .^{13}$

$$
u_{t}^{i}=\left\{\begin{array}{cc}
c_{t}^{i}+\gamma n_{t}^{i} & \text { for } i=1 \\
\left(c_{t}^{i}\right)^{1-\theta}+\gamma n_{t}^{i} & \text { for } i=2,
\end{array}\right.
$$

where $\gamma>1$, and $\theta>1$ is the degree of risk aversion which also governs the elasticity of substitution. The higher is $\theta$ the more risk-averse is type $2 .{ }^{14}$ Differences in the risk attitude are the only source of heterogeneity within a generation and the distribution of types changes therefore due to the effect of natural selection.

\footnotetext{
12 The modeling of the production side is based upon two simplifying assumptions. First, capital is not an input in the production function, and second the return to land is zero. Alternatively it could have been assumed that the economy is small and open to a world capital market in which the interest rate is constant. In this case, the quantity of capital will equalize its marginal product to the interest rate, while the price of land will follow a path such that the total return on land (rent plus net price appreciation) will be equal to the interest rate. Allowing for capital accumulation and property rights over land would complicate the model to the point of intractability, but would not affect the qualitative results.

${ }^{13}$ For simplicity, the analysis abstracts from child mortality risk. Alternatively one can interpret the preferences such that parents derive utility from the expected number of surviving offspring and the cost of child rearing is associated only with surviving children. ${ }^{14}$ The linearity of the utility function with respect to the number of children, reflects the fact that as shown in Section 5 risk neutrality with respect to children is the trait that will be selected in the long-run. Moreover, allowing for $0<\theta \leq 1$ will not effect the qualitative results. However, $0<\theta<1$ will result in the undesirable extinction of the population in the long run, and $\theta=1$ will add an additional case to be considered without any additional insights.
} 
Individuals allocate their income, $y_{t}^{i}$, between consumption, $c_{t}^{i}$, and expenditure on child rearing. The cost of raising a child is assumed to be a fraction $\tau<1 / 2$ of the level of output per worker in the economy, $y_{t} \cdot{ }^{15}$ Hence, individual $i$ 's budget constraint is

$$
y_{t} \tau n_{t}^{i}+c_{t}^{i} \leq y_{t}^{i},
$$

where $y_{t} \tau n_{t}^{i}$ is the cost of raising $n_{t}^{i}$ children in period $t$.

\subsection{Innovations}

In each period $t$ individual $i$ can be engaged in either safe or risky production. Individual $i$ can use the safe production technology in period $t, A_{t}$, that reflects the successful modes of production of the previous period. Individual $i$ that operates under this safe production mode generates income $y_{t}^{i}=\left[\left(A_{t} X\right) / L_{t}\right]^{\alpha}$. Alternatively, individual $i$ may choose to experiment with a risky technology. If the experimentation is successful the individual will operate with a superior production technology, $A_{t}^{H}>A_{t}$, and will generate a higher income, $y_{t}^{i, H}=\left[\left(A_{t}^{H} X\right) / L_{t}\right]^{\alpha}>y_{t}$. However, if the experimentation is unsuccessful the individual will operate with an inferior production technology, $A_{t}^{L}>A_{t}$, and will generate a lower income, $y_{t}^{i, L}=\left[\left(A_{t}^{L} X\right) / L_{t}\right]^{\alpha}>y_{t}$.

Let $p$ be the probability of successful experimentation. Suppose that the expected return associated with the risky production mode is equal to the one associated with the safe mode of production. Namely, ${ }^{16}$

$$
p A_{t}^{H}+(1-p) A_{t}^{L}=A_{t}
$$

Individual $i$ will be engaged in the risky production mode as long as expected utility from the risky production mode is at least as large as the utility from the safe one. Thus it follows from (5) that risk-averse -type 2 -individuals will choose the safe mode of production, reflecting the fact that the (non-compensated) variance of the expected income deters experimentation with risky productive methods. Consequently, individuals of type 2 will generate income equal to the average income in the economy in period $t$, i.e.,

$$
y_{t}^{2}=y_{t}
$$

Risk-neutral -type 1 -individuals, on the other hand, because of their constant marginal utility with respect to consumption and fertility, undertake the risky production mode.

\footnotetext{
15 Thus, the cost of child rearing is indexed to the income of the average person in each generation.

${ }^{16}$ The assumption imposed on the returns to innovation is deliberately chosen to abstract from lifetime income heterogeneity across types. Allowing for entrepreneurial activity to generate higher expected income, in an era in which the latter is converted into larger number of surviving offspring, would accentuate the evolutionary advantage of the growth-promoting type. Moreover, as it will become apparent, in advanced stages of economic development higher income would not have a positive effect on fertility for the riskneutral type and thus the selection of entrepreneurial traits would not be affected.
} 
Hence, a fraction $p$ of the risk-neutral individuals will generate higher income than the riskaverse type, whereas a fraction $(1-p)$ will generate lower income. In particular,

$$
y_{t}^{1}= \begin{cases}y_{t}^{1, H} & \text { with probability } p \\ y_{t}^{1, L} & \text { with probability } 1-p\end{cases}
$$

It follows from (5) that the average income across the two types will be the same in each period $t$. Nevertheless, the engagement of the risk-neutral type in risky technological innovations affects the technology that is available to the next generation. In particular, new productive knowledge will be generated by a fraction $p$ of risk-neutral individuals and subsequent generations reap the technological benefits of this experimentation. Thus, societies dominated by risk-averse individuals are associated with lower degree of experimentation, passively transmitting the existing productive knowledge from one generation to the next.

\subsection{Optimization}

2.4.1 The Risk-Averse Type-The risk-averse -type 2 -in generation $t$ chooses the number of children, and therefore personal consumption, so as to maximize the utility function (3), subject to the budget constraint (4). Namely:

$$
n_{t}^{2}=\operatorname{argmax}\left\{\frac{\left(c_{t}^{2}\right)^{(1-\theta)}}{1-\theta}+\gamma n_{t}^{2}\right\}
$$

subject to:

$$
\begin{aligned}
c_{t}^{2} & =y_{t}\left(1-\tau n_{t}^{2}\right) \geq 0 ; \\
n_{t}^{2} & \geq 0 .
\end{aligned}
$$

The consumption of individual of type 2 as a function of the income level $y_{t}$ is:

$$
c_{t}^{2}\left(y_{t}\right)=\left(\tau y_{t} / \gamma\right)^{1 / \theta},
$$

where $\partial c_{t}^{2} / \partial y_{t}>0$.

The number of children of individual of type 2 as a function of the income level $y_{t}$ is:

$$
n_{t}^{2}=n\left(y_{t}\right) \equiv\left\{\begin{array}{cl}
0 & \text { if } \quad y_{t} \leq(\gamma / \tau)^{1 /(1-\theta)} \equiv \tilde{y} \\
{\left[1-(\tau / \gamma)^{1 / \theta} y_{t}^{(1-\theta) / \theta}\right] / \tau} & \text { if } \quad y_{t}>(\gamma / \tau)^{1 /(1-\theta)} \equiv \tilde{y}
\end{array}\right.
$$

Hence, as depicted in Figure 1, the fertility rate of individuals of type 2 in period $t, y_{t}^{2}$, is a weakly increasing, concave function of $y_{t}$. 


$$
\frac{\partial n_{t}^{2}}{\partial y_{t}}=\left\{\begin{array}{ccc}
0 & \text { if } & y_{t}<(\gamma / \tau)^{1 /(1-\theta)} \\
{\left[(\theta-1)(\tau / \gamma)^{1 / \theta} y_{t}^{(1-2 \theta) / \theta}\right] / \theta \tau} & \text { if } & y_{t}>(\gamma / \tau)^{1 /(1-\theta)}
\end{array}\right.
$$

Lemma 1: Fertility is above replacement for individuals of type 2 if income per worker exceeds $\gamma / \tau$, i.e.,

$$
n^{2}\left(y_{t}\right)>1 \quad \text { if } \quad y_{t} \geq \gamma / \tau
$$

Proof: See Appendix.

2.4.2 The Risk-Neutral Type-As established in Section 2.3 risk-neutral individuals engage in experimentation which yields higher or lower income depending on whether their innovation efforts are successful. Hence, there is income heterogeneity within type 1 where each individual $j$ of type 1 generates income $y_{t}^{1, j}$ with $j=\{H, L\}$.

Individual $j$ of type 1 in period $t$ chooses the number of children and therefore own consumption, so as to maximize (3) subject to (4):

$$
n_{t}^{1, j}=\operatorname{argmax}\left\{c_{t}^{1, j}+\gamma n_{t}^{1, j}\right\}
$$

subject to

$$
\begin{aligned}
c_{t}^{1, j} & =y_{t}^{1, j}-y_{t} \tau n_{t}^{1, j} \geq 0 \\
n_{t}^{1, j} & \geq 0
\end{aligned}
$$

The consumption of individual $j$ of type 1 as a function of the income level $y_{t}^{1, j}$ is:

$$
c_{t}^{1, j}=c_{t}\left(y_{t}^{1, j} ; y_{t}\right) \equiv\left\{\begin{array}{cll}
0 & \text { if } & 0<y_{t}<\gamma / \tau \\
y_{t}^{1, j} & \text { if } & y_{t}>\gamma / \tau
\end{array}\right.
$$

where $\partial c_{t}^{1, j} / \partial y_{t}^{1, j} \geq 0$

The number of children of an individual $j$ of type 1 as a function of the income level $y_{t}^{1, j}$ is:

$$
n_{t}^{1, j}=n\left(y_{t}^{1, j}, y_{t}\right) \equiv\left\{\begin{array}{lll}
\left(y_{t}^{1, j} / \tau y_{t}\right) & \text { if } & 0<y_{t}<\gamma / \tau \\
0 & \text { if } & y_{t}>\gamma / \tau
\end{array}\right.
$$

At low stages of development, when average income is sufficiently low (i.e., $y_{t}<\gamma / \tau$ ) the relative cost of raising a child, $\lambda y_{t}$, is lower than $\gamma$ (i.e., the marginal rate of substitution between consumption and fertility) and risk-neutral individuals allocate all resources to children. As the economy develops and average income increases, the relative cost of raising a child increases. Thus, at sufficiently high stages of development (i.e., $y_{t}>\gamma / \tau$ ) the relative 
cost of raising a child, $x y_{t}$, is higher than $\gamma$ and risk-neutral individuals allocate all resources towards own consumption.

The fertility rate of individual $j$ of type 1 in period $t, n_{t}^{1 . j}$, is a non-negative, non-decreasing function of the income, $y_{t}^{1, j}$. In particular,

$$
\frac{\partial n_{t}^{1, j}}{\partial y_{t}^{1, j}}=\left\{\begin{array}{lll}
1 / \tau y_{t} & \text { if } & 0<y_{t}<\gamma / \tau \\
0 & \text { if } & y_{t}>\gamma / \tau
\end{array},\right.
$$

and $\partial^{2} n_{t}^{1, j} / \partial^{2} y_{t}^{1, j}=0$

\section{The Process of Development}

The process of development is governed by the time path of the level of technology, income per worker and the composition of the risk attitudes in the population.

\subsection{The Evolution in the Composition of Types}

Suppose that at time 0 the economy consists of a continuum of individuals of mass of $L_{0}$, where $\beta_{o}$ represents the fraction of type 1 in the population.

In accordance with the historical pattern of fertility, income per worker is assumed to be sufficiently high in every period, so as to assure that fertility rates are positive for both types in the population. Hence in light of (10) it is assumed that income per-worker in period 0 is sufficient to allow the risk-averse type to allocate positive resources towards child-rearing, i.e. $y_{0}>\tilde{y}$.

The evolution of the fraction of the risk-neutral traits in the population over time is determined by the average fertility rates of the two types of individuals. As derived in (10), since there is no income heterogeneity across individuals of type 2, fertility of each individual of type 2 is $n_{t}^{2}$. However, income and thus fertility decisions differ across successful and non-successful individuals of type 1 . In particular, the average fertility across individuals of type 1 in each period $t$ is:

$$
n_{t}^{1}=p n_{t}^{1, H}+(1-p) n_{t}^{1, L}, \quad(16)
$$

where $n_{t}^{1, L}$ and $n_{t}^{1, H}$ are given in (14).

Lemma 2-The average fertility of a risk-neutral individual -type 1 -in the process of development is:

$$
n_{t}^{1}=n_{t}^{1}\left(y_{t}\right) \equiv\left\{\begin{array}{lll}
1 / \tau & \text { if } & 0<y_{t}<\gamma / \tau \\
0 & \text { if } & y_{t}>\gamma / \tau
\end{array}\right.
$$

Proof-Follows from (14) and (16). 
The subsequent corollary follows from (10) and Lemma 2.

Corollary 1-For a given level of average income $y_{t}$ in period $t$

$$
n_{t}^{1}\left(y_{t}\right)=\left\{\begin{array}{lll}
>n_{t}^{2}\left(y_{t}\right) & \text { if } & 0<y_{t}<\gamma / \tau \\
<n_{t}^{2}\left(y_{t}\right) & \text { if } & y_{t}>\gamma / \tau
\end{array}\right.
$$

Hence, as depicted in Figure 1, in early stages of development (i.e., $0<y_{t}<\gamma / \tau$ ), the entrepreneurial types -type 1 -have an evolutionary advantage, whereas as soon as the economy progresses sufficiently (i.e., $y_{t}>\gamma / \tau$ ), the risk-averse individuals -type 2 -gain the evolutionary advantage.

Given the size of the population in period $t, L_{t}$, the size of the population in period $t+1, L_{t+1}$, is:

$$
L_{t+1}=n_{t}^{1} \beta_{t} L_{t}+n_{t}^{2}\left(1-\beta_{t}\right) L_{t}
$$

where $\beta t$ is the fraction of risk-neutral individuals (type 1 ) in the population and $n_{t}^{1}$ and $n_{t}^{2}$ denote the average fertility for types 1 and type 2 , respectively.

The fraction of individuals of type 1 in the population in period $t+1, \beta_{t+1}$, is therefore:

$$
\beta_{t+1}=\frac{\beta_{t} n_{t}^{1}}{\beta_{t} n_{t}^{1}+\left(1-\beta_{t}\right) n_{t}^{2}}
$$

Hence, it follows from (10) and (14) that

$$
\beta_{t+1}=\phi\left(\beta_{t}, y_{t}\right) \equiv\left\{\begin{array}{lll}
\frac{\beta_{t}}{\beta_{t}+\left(1-\beta_{t}\right)\left[1-(\tau / \gamma)^{(1 / \theta)} y_{t}^{(1-\theta) / \theta}\right]} & \text { if } 0<y_{t}<\gamma / \tau \\
0 & \text { if } y_{t}>\gamma / \tau
\end{array}\right.
$$

Lemma 3-The Properties of $\varphi\left(\beta_{t}, y_{t}\right)$

For $y_{t}<\gamma / \tau$

$$
\begin{array}{ll}
\text { 1. } & \phi\left(0, y_{t}\right)=0 \quad \text { and } \quad \phi\left(1, y_{t}\right)=1 \\
\text { 2. } & \phi_{\beta}\left(\beta_{t}, y_{t}\right)>0 \text { and } \phi_{\beta \beta}\left(\beta_{t}, y_{t}\right)<0 .
\end{array}
$$

Proof-See Appendix.

Hence, as depicted in Figure 2, for a given level of income per worker, $y_{t}$, the fraction of risk-neutral individuals in the population increases monotonically over time and approaches 1 , if $0<y_{t}<\gamma / \tau$, whereas this fraction vanishes, once $y_{t}>\gamma / \tau$. 


\subsection{Technological Progress}

As established in section 2.3, technological progress, $g_{t+1}$, that takes place between periods $t$ and $t+1$ depends on the fraction of risk-neutral individuals, within the working generation in period $t, \beta_{t}$. Furthermore, it is assumed to be a function of the level of income per worker in period $t, y_{t}$. Namely, ${ }^{17}$

$$
g_{t+1} \equiv \frac{A_{t+1}-A_{t}}{A_{t}}=g\left(\beta_{t}, y_{t}\right)
$$

Suppose the rate of technological progress between period $t$ and $t+1$ is a (weakly) positive, (weakly) increasing, concave function of the fraction of entrepreneurial individuals among the working generation at time $t$ and the level of income per-worker, i.e.,

$$
\begin{array}{ll}
g_{y}\left(\beta_{t}, y_{t}\right) \geq 0 \text { and } g_{y y}\left(\beta_{t}, y_{t}\right) \leq 0 & \forall \beta_{t} \in[0,1] \text { and } \forall y_{t}>0 \\
g_{\beta}\left(\beta_{t}, y_{t}\right) \geq 0 \text { nd } g_{\beta \beta}\left(\beta_{t}, y_{t}\right) \leq 0 & \forall \beta_{t} \in[0,1) \text { and } \forall y_{t}>0
\end{array} \text {. }
$$

The time path of the level of technology is given therefore by:

$$
A_{t+1}=\left(1+g_{t+1}\right) A_{t}
$$

where the level of technology at time 0 is given at a level $A_{0}$.

\subsection{The Time Path of Income Per Worker}

As follows from (2), (17), (20) and (21) income per worker in period $t+1$ is:

$$
y_{t+1}=\left(\frac{A_{t+1} X}{L_{t+1}}\right)^{\alpha}=\left(\frac{A_{t} X}{L_{t}}\right)^{\alpha}\left(\frac{\left[1+g\left(\beta_{t}, y_{t}\right)\right]}{\beta_{t} n_{t}^{1}+\left(1-\beta_{t}\right) n_{t}^{2}}\right)^{\alpha} \text {. }
$$

Thus,

$$
y_{t+1}=y_{t}\left(\frac{\left[1+g\left(\beta_{t}, y_{t}\right)\right]}{\left.\beta_{t} n_{t}^{1}+\left(1-\beta_{t}\right) n_{t}^{2}\right)}\right)^{\alpha} \text {. }
$$

Hence, it follows from (10) and Lemma 2 that the income per worker in period $t+1$ is determined by the level of income per worker in period $t, y_{t}$, and the fraction of entrepreneurial individuals in the adult population, $\beta_{t}$.

$$
y_{t+1}=\psi\left(\beta_{t}, y_{t}\right) \text {, }
$$

where

\footnotetext{
${ }^{17}$ The positive role of income per capita in technological progress is well established. In a Malthusian environment, a higher level of income per capita will be associated with a larger population that would have a positive effect on the supply, the demand, and the diffusion of knowledge. Moreover, it will foster specialization and trade and will therefore enhance technological progress. In the industrial world higher income per capita will support a more educated population that is more likely to implement new technologies, and will generate a wider tax base that would permit extensive investment in infrastructure, education and research.
} 


$$
\psi\left(\beta_{t}, y_{t}\right) \equiv \begin{cases}y_{t}\left[\frac{\left[1+g\left(\beta_{t}, y_{t}\right)\right]}{\left\{\beta_{t}+\left(1-\beta_{t}\right)\left[1-(\tau / \gamma)^{1 / \theta} y_{t}^{(1-\theta) / \theta}\right]\right\} / \tau}\right]^{\alpha} & \text { if } \quad 0<y_{t}<\gamma / \tau \\ y_{t}\left[\frac{\left[1+g\left(0, y_{t}\right)\right]}{\left[1-(\tau / \gamma)^{1 / \theta} y_{t}^{(1-\theta) / \theta}\right] / \tau}\right]^{\alpha} & \text { if } \quad y_{t}>\gamma / \tau .\end{cases}
$$

An increase in the fraction of the entrepreneurial individuals, $\beta_{t}$, has unambiguously positive effects on the level of income per worker in period $t+1, y_{t+1}=\left(A_{t+1} X / L_{t+1}\right)^{a}$, in an environment where risk neutrality is conducive to individuals reproducing at lower rates, (i.e., when $y_{t}>\gamma / \tau$ ). It raises the level of technology in period $t+1$, and reduces the population growth rate between periods $t$ and $t+1$. However, when $y_{t}<\gamma / \tau$ and thus the entrepreneurial type reproduces at a higher rate, an increase in the fraction of these individuals (type 1) in period $t$ has an ambiguous effect on output per-worker in $t+1$ since it has a positive effect on both the level of technology and population in period $t+1$.

An increase in output per worker, $y_{t}$, has ambiguous effects on the level of income per worker in period $t+1$. On the one hand, it increases the level of technology in the next period, $A_{t+1}$, positively affecting output per worker, but on the other hand, it increases fertility rates in period $t$, and thus the size of the population in period $t+1$, adversely affecting income per worker.

\section{The Dynamical System}

The evolution of the economy is fully determined by the evolution of the fraction of riskneutral individuals, $\beta_{t}$, and the level of output per worker, $y_{t}$. It is given by the sequence $\left\{\beta_{t}, y_{t}\right\}_{t=0}^{\infty}$ that is governed by the two-dimensional non-linear discrete dynamical system:

$$
\begin{aligned}
& \beta_{t+1}=\phi\left(\beta_{t}, y_{t}\right) \\
& y_{t+1}=\psi\left(\beta_{t}, y_{t}\right)
\end{aligned}
$$

where $\left(\beta_{0}, y_{0}\right)$ is given.

The analysis of this two-dimensional dynamical system will require the derivation of its phase diagram, based on the characterization of the $\beta \beta$ locus under which $\beta_{t}$ is in a steadystate, the $y y$ locus under which $y_{t}$ is in a steady-state, and the forces that operate on the system when the variables are not in a steady-state equilibrium.

\subsection{The $\beta \beta$ locus}

The $\beta \beta$ locus is the geometric locus of all pairs $\left(\beta_{t}, y_{t}\right)$ such that $\beta_{t}$ is in a steady state.

$$
\beta \beta \equiv\left\{\left(\beta_{t}, y_{t}\right): \beta_{t+1}-\beta_{t}=0\right\}
$$

As follows from (19), along the $\beta \beta$ locus 


$$
\phi\left(\beta_{t}, y_{t}\right)-\beta_{t}=0
$$

Lemma 4-The properties of the $\beta \beta$ locus:

$$
\beta_{t+1}-\beta_{t}\left\{\begin{array}{ccc}
>0 & \text { if } & 0<y_{t}<\gamma / \tau \& \beta \epsilon(0,1) \\
=0 & \text { if } & {\left[\beta_{t}=0\right] \text { or }\left[\beta_{t}=1 \& y_{t}<\gamma / \tau\right]} \\
<0 & \text { if } & y_{t}>\gamma / \tau \& \beta \epsilon(0,1] .
\end{array}\right.
$$

Proof-As follows from (18)

$$
\beta_{t+1}-\beta_{t}=\frac{\beta_{t}\left(1-\beta_{t}\right)\left[n^{1}\left(y_{t}\right)-n^{2}\left(y_{t}\right)\right]}{\beta_{t} n^{1}\left(y_{t}\right)+\left(1-\beta_{1}\right) n^{2}\left(y_{t}\right)} .
$$

Hence, as follows from Corollary 1:

$$
\beta_{t+1}-\beta_{t}=\left\{\begin{array}{lll}
>0 & \text { if } & 0<y_{t} \leq \gamma / \tau \& \beta \epsilon(0,1) \\
=0 & \text { if } & {\left[\beta_{t}=0\right] \text { or }\left[\beta_{t}=1 \& y_{t} \leq \gamma / \tau\right]} \\
<0 & \text { if } & y_{t}>\gamma / \tau \& \beta \epsilon(0,1]
\end{array}\right.
$$

As depicted in Figure 3, the fraction of risk-neutral individuals, $\beta_{t}$, is in a steady state if:

a. (a) $\beta_{t}=0$ i.e., there are only individuals of type 2 in the population and thus there are only individuals of type 2 in all future periods.

b. (b) $\beta_{t}=1$ i.e., there are only individuals of type 1 in the population and average income in the population is less than $\beta / \tau$.

\subsection{The Replacement Locus - yy ${ }^{R}$}

The replacement frontier $y y^{R}$, as depicted in Figure 3, is the geometric locus of all pairs $\left(\beta_{t}\right.$, $y_{t}$ ) such that the average level of fertility is at replacement level, i.e.,

$$
y y^{R} \equiv\left\{\left(\beta_{t}, y_{t}\right): \beta_{t} n^{1}\left(y_{t}\right)+\left(1-\beta_{t}\right) n^{2}\left(y_{t}\right)=1\right\} .
$$

Lemma 5-The properties of the replacement locus - yy ${ }^{\mathrm{R}}$

1. There exists a continuous single-valued function, $\mathrm{y}^{\mathrm{R}}\left(\beta_{t}\right)$, such that given $\left(\beta_{t}, y^{R}\left(\beta_{t}\right)\right)$ the average fertility level is at replacement, i.e.,

$$
\left(\beta_{t}, y^{R}\left(\beta_{t}\right)\right) \in y y^{R} \quad \forall \beta_{t} \in[0, \tau],
$$

where 


$$
\begin{aligned}
y^{R}(\tau) & =\tilde{y} \\
y^{R}\left(\beta_{t}\right) & <\gamma / \tau
\end{aligned} \quad \forall \beta_{t} \in[0, \tau] .
$$

2. The level of income that corresponds to replacement fertility, $\mathrm{y}^{\mathrm{R}}\left(\beta_{t}\right)$, is monotonically decreasing in the fraction of entrepreneurial individuals, $\beta_{\mathrm{t}}$ i.e.,

$$
\left.\frac{\partial y^{R}\left(\beta_{t}\right)}{\partial \beta_{t}}\right|_{y y^{R}}<0 \quad \forall \beta_{t} \in[0, \tau] .
$$

3. The average level of fertility is below replacement if and only if $y_{t}<y_{t}^{R}\left(\beta_{t}\right)$ and above replacement if and only if $y_{t}>y^{R}\left(\beta_{t}\right)$, i.e.,

$$
\begin{array}{llll}
\beta_{t} n^{1}\left(y_{t}\right)+\left(1-\beta_{t}\right) n^{2}\left(y_{t}\right)<1 & \text { iff } & y_{t}<y_{t}^{R}\left(\beta_{t}\right) \\
\beta_{t} n^{1}\left(y_{t}\right)+\left(1-\beta_{t}\right) n^{2}\left(y_{t}\right)>1 & \text { iff } & y_{t}>y_{t}^{R}\left(\beta_{t}\right)
\end{array} .
$$

\section{Proof-See Appendix.}

The replacement locus, depicted in Figure 3, is downward sloping. ${ }^{18}$ As established in Corollary 1 , for an income below $\gamma / \tau$, as the fraction of the risk-neutral individuals, $\beta_{t}$, increases, fertility increases and thus the level of income that is needed to support replacement fertility, $y^{R}\left(\beta_{t}\right)$, is lower.

\subsection{The yy locus}

The $y y$ locus is the geometric locus of all pairs $\left(\beta_{t}, y_{t}\right)$ such that $y_{t}$ is in a steady state,

$$
y y \equiv\left\{\left(\beta_{t}, y_{t}\right): y_{t+1}-y_{t}=0\right\} \text {. }
$$

As follows from (23) and (25), along the yy locus

$$
\psi\left(\beta_{t}, y_{t}\right)-y_{t}=y_{t}\left[\left(\frac{\left(1+g\left(\beta_{t}, y_{t}\right)\right)}{\beta_{t} n^{1}\left(y_{t}\right)+\left(1-\beta_{t}\right) n^{2}\left(y_{t}\right)}\right)^{\alpha}-1\right]=0 .
$$

Hence,

$$
y_{t+1}-y_{t} \gtreqless 0 \Longleftrightarrow 1+g\left(\beta_{t}, y_{t}\right) \gtreqless\left[\beta_{t} n^{1}\left(y_{t}\right)+\left(1-\beta_{t}\right) n^{2}\left(y_{t}\right)\right] .
$$

In order to simplify the exposition and to assure that the economy may escape from the Malthusian trap, few boundary conditions are imposed on the function $g\left(\beta_{t}, y_{t}\right)$.

${ }^{18}$ Without loss of generality, Figure 3 is drawn under the assumption that the $y y{ }^{R}$ locus is convex. Note, however that as long as the locus is downward sloping the qualitative analysis remains intact. 


$$
\begin{aligned}
& g_{\beta}\left(\beta_{t}, y_{t}\right)<n^{1}\left(y_{t}\right)-n^{2}\left(y_{t}\right) \quad \text { for } y_{t} \in(0, \tilde{y}] \quad \text { if and only if } \beta_{t} \in[0, \tilde{\beta}] \text {; } \\
& g_{y}\left(\beta_{t}, y_{t}\right)<\beta_{t} \frac{\partial n^{1}\left(y_{t}\right)}{\partial y_{t}}+\left(1-\beta_{t}\right) \frac{\partial n^{2}\left(y_{t}\right)}{\partial y_{t}} \quad \text { if and only if } y_{t} \in(0, \tilde{y}] ; \quad \text { ((A2)) } \\
& g\left(\beta_{t}, y_{t}\right)=\left\{\begin{array}{l}
=0 \\
>0
\end{array} \quad \text { if and only if } \begin{array}{l}
y_{t} \leq y^{R}\left(\beta_{t}\right) \\
y_{t}>y^{R}\left(\beta_{t}\right)
\end{array}\right.
\end{aligned}
$$

where $\breve{\beta} \in(0, \tau)$ and $\breve{y}=y(\breve{\beta}) \in\left(y^{R}\right) \in\left(y^{R}\left(\beta_{t}\right), \gamma / \tau\right)$.

Lemma 6-The properties of the yy locus.

$\operatorname{Under}(A 1)$ and (A2)

1. There exists a continuous single-valued function, $\mathrm{y}^{\mathrm{R}}\left(\beta_{t}\right)$, such that

$$
\left(\beta_{t}, y^{R}\left(\beta_{t}\right)\right) \in y y \quad \forall \beta_{t} \in[0, \tau]
$$

2. There exists a decreasing continuous, single-valued function $\mathrm{y}\left(\beta_{t}\right) \in\left(y^{R}\left(\beta_{t}\right), \gamma / \tau\right)$ such that

$$
\begin{array}{r}
\left(\beta_{y}, y\left(\beta_{t}\right)\right) \in y y \quad \text { and } y^{\prime}\left(\beta_{t}\right)<0 \quad \forall \beta_{t} \in[0, \hat{\beta}) \\
\text { where }^{\lim _{\beta_{t} \rightarrow \hat{\beta}} y\left(\beta_{t}\right)=y^{R}(\hat{\beta}), y(0) \in(\breve{y}, \gamma / \tau), \text { and }} \hat{\beta} \in[\breve{\beta}, \tau) .
\end{array}
$$

3.

$$
y_{t+1}-y_{t}\left\{\begin{array}{lll}
<0 & \text { iff } & y^{R}\left(\beta_{t}\right)<y_{t}<y\left(\beta_{t}\right) \text { and } \beta_{t} \in[0, \hat{\beta}) \\
>0 & & \text { otherwise }
\end{array}\right.
$$

Proof-See Appendix.

The $y y$ locus is depicted in Figure 3. The yy locus consists of two downward sloping segments: (i) the replacement locus, $y y^{R}$, and (ii) a single valued function $y\left(\beta_{t}\right)$ that intersects the $y y^{R}$ locus at $\hat{\beta}$ and the $\beta \beta$ locus at $(0, y(0))$.

\subsection{Steady-State Equilibria}

Steady-state equilibria of the dynamical system are pairs $(\bar{\beta}, \bar{y})$ such that:

$$
\begin{aligned}
& \bar{\beta}=\phi(\bar{\beta}, \bar{y}) \\
& \bar{y}=\psi(\bar{\beta}, \bar{y}) .
\end{aligned}
$$


Hence a steady-state equilibrium is characterized by an intersection of the $\beta \beta$ locus and the yy locus. As depicted in Figure 3, the system is characterized by two steady-state equilibria.

Lemma 7-The dynamical system has two steady-state equilibria:

$$
(\bar{\beta}, \bar{y})=\left\{(0, y(0)),\left(0, y^{R}(0)\right)\right\} \text {. }
$$

The steady-state equilibria: $(0, y(0))$ is unstable, and $\left(0, y^{R}(0)\right)$ is a saddle.

$$
\lim _{t \rightarrow \infty}\left(\beta_{t}, y_{t}\right)=\left(0, y^{R}(0)\right) \text { if and only if } \beta_{0}=0 \& y_{t}<y(0) .
$$

Proof-The lemma follows from the properties of the $\beta \beta$ locus and the $y y$ locus as established in Lemmas 4 and 6, and as depicted in Figure 3.

Corollary 2-If the initial fraction of the entrepreneurial individuals is greater than zero, i.e., if $\beta_{0}>0$, then in the long-run the fraction of entrepreneurial individuals vanishes asymptotically, whereas the level of output per-worker grows indefinitely, i.e.,

$$
\lim _{t \rightarrow \infty}\left(\beta_{t}, y_{t}\right)=(0, \infty) \quad \text { if } \beta_{0}>0 .
$$

Proof-The corollary follows from Lemmas 4-7, and the implied motion in Figure 3.

\subsection{The Evolution of Entrepreneurial Spirit and the Process of Development}

Suppose, without loss of generality, that the economy starts with an income per-worker, $y^{R}\left(\beta_{0}\right)$, that is just sufficient to generate replacement fertility, as was the case during the Malthusian epoch. That is, the economy starts on the $y y^{R}$ locus. Suppose further that there is a small fraction of risk-neutral individuals in the economy, $\beta_{0}<\hat{\beta}$. As depicted in Figure 3 , the forces of natural selection will increase the representation of these risk-neutral growth promoting individuals in society, and once this fraction will exceed the critical level $\hat{\beta}$, income will increase monotonically along with the fraction of the risk-neutral entrepreneurial traits. Once the level of income per-worker increases above the threshold level of income $\gamma / \tau$, the evolutionary advantage is reversed. Risk-averse individuals generate an evolutionary advantage and $\beta$ declines to 0 .

Interestingly, in the absence of the forces of natural selection the economy will remain indefinitely in a Malthusian equilibrium. That is, if entrepreneurial traits are not hereditary and the distribution of types remains unchanged over time, the level of income per worker will remain at a level $y^{R}\left(\beta_{0}\right)$, where fertility is at replacement. This will constitute a stable Malthusian equilibrium. 


\section{Variations in the Risk Attitude Towards Children}

This section demonstrates that risk neutrality with respect to children is the type of behavior that would be selected in populations that have been expanding over time, and thus the utility function that is adopted in the main analysis is the appropriate one.

Suppose that preferences of individuals $i$ are represented by a utility function with constant relative risk aversion with respect to consumption, $\theta$, and (heterogeneous) risk attitudes with respect to children, $\lambda_{i}$,

$$
u_{t}^{i}=\frac{\left(c_{t}^{i}\right)^{1-\theta}}{1-\theta}+\gamma \frac{\left(n_{t}^{i}\right)^{1-\lambda_{i}}}{1-\lambda_{i}} ; \quad \lambda_{i} \geq 0
$$

Members of generation $t$ choose the number of children, and therefore own consumption to maximize the utility function (32) subject to the budget constraint. Thus, the optimization problem of a member of generation $t$ is:

$$
n_{t}^{i}=\operatorname{argmax}\left\{\frac{\left(c_{t}^{i}\right)^{1-\theta}}{1-\theta}+\gamma \frac{\left(n_{t}^{i}\right)^{1-\lambda_{i}}}{1-\lambda_{i}}\right\} .
$$

Subject to:

$$
\begin{aligned}
c_{t}^{i} & =y_{t}\left(1-n_{t}^{i} \tau\right) \geq 0 \\
n_{t}^{i} & \geq 0 .
\end{aligned}
$$

The solution of the optimization problem is interior. It is given by the implicit function:

$$
F\left(n_{t}^{i}, \lambda_{i}\right)=\gamma\left(n_{t}^{i}\right)^{-\lambda_{i}}-y_{t} \tau\left[y_{t}\left(1-n_{t}^{i} \tau\right)\right]^{-\theta} \equiv 0 .
$$

As established in the following Lemma, as long as fertility rates are above replacement the more risk tolerant type in terms of children has the evolutionary advantage. If fertility rates are below replacement (and the population therefore vanishes over time), the type that is more risk-averse with respect to children gains an evolutionary advantage.

\section{Lemma 8}

The effect of risk aversion with respect to fertility on reproductive success is negative as long as fertility is above replacement and is positive as long as fertility is below replacement.

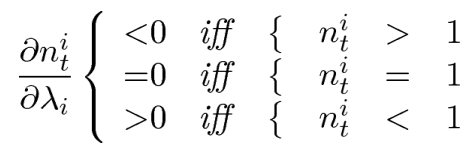


Proof

Using the Implicit Function Theorem, it follows from (34) that:

$$
\frac{\partial n_{t}^{i}}{\partial \lambda_{i}}=-\frac{\partial F\left(n_{t}^{i}, \lambda_{i}\right) / \partial \lambda_{i}}{\partial F\left(n_{t}^{i}, \lambda_{i}\right) / \partial n_{t}^{i}}=-\frac{-\gamma\left(n_{t}^{i}\right)^{-\lambda_{i}} \ln n_{t}^{i}}{-\lambda \gamma\left(n_{t}^{i}\right)^{-\lambda_{i}-1}-\theta\left(y_{t} \tau\right)^{2}\left[y_{t}\left(1-n_{t}^{i} \tau\right)\right]^{-\theta-1}} .
$$

where,

$$
\begin{array}{llll}
\frac{\partial F\left(n_{t}^{i}, \lambda_{i}\right)}{\partial \lambda_{i}} & \left\{\begin{array}{lll}
<0 & \text { if } & n_{t}^{i}>1 \\
>0 & \text { if } & n_{t}^{i}<1
\end{array}\right. \\
\frac{\partial F\left(n_{t}^{i}, \lambda_{i}\right)}{\partial n_{t}^{i}} & <0 .
\end{array}
$$

Hence,

$$
\operatorname{sign}\left[\frac{\partial n_{t}^{i}}{\partial \lambda_{i}}\right]=\operatorname{sign}\left[\frac{\partial F\left(n_{t}^{i}, \lambda_{i}\right)}{\partial \lambda_{i}}\right]\left\{\begin{array}{ccc}
>0 & \text { if } & n_{t}^{i}<1 \\
<0 & \text { if } & n_{t}^{i}>1
\end{array} .\right.
$$

Thus the lemma follows from (37).

Since the human population has not become extinct, fertility has not been below replacement and the distribution of risk attitudes with respect to children converges towards risk-neutrality in the long-run. ${ }^{19}$

\section{Corollary 3}

Risk neutrality with respect to children, i.e., $\lambda_{i}=0$, will be selected in the long-run.

Hence, risk neutrality with respect to children that was imposed on the utility function in the main part of the paper, is the trait that will be selected in the long-run.

\section{Concluding Remarks}

This research suggests that a Darwinian evolution of entrepreneurial spirit played a significant role in the process of economic development and the evolution of inequality within and across societies. The study argues that entrepreneurial spirit evolved nonmonotonically in the course of human history. In early stages of development, risk-tolerant, growth promoting traits generated an evolutionary advantage and their increased representation accelerated the pace of technological advancements and the process of economic development. In mature stages of development, however, risk-averse individuals gained an evolutionary advantage diminishing the growth potential of advanced economies.

The research identifies a novel force that operates towards a convergence of developing economies to the richer ones. Unlike the commonly underlined forces of economic

\footnotetext{
${ }^{19}$ Segments of the human population that have been shrinking over time, but have not become extinct, would compose of more risk averse individuals with respect to fertility.
} 
convergence, the research suggests that convergence is triggered by the higher prevalence of individuals with entrepreneurial traits in lower income economies.

The prediction of the theory regarding the evolution of inequality and entrepreneurial activities within a society is consistent with the pattern observed in England during the course of the Industrial Revolution. In particular the theory suggests that the failure of the landed aristocracy to lead the innovative process of industrialization could be attributed to the low representation of entrepreneurial individuals within this group, and the prevalence of individuals with entrepreneurial traits among the middle and the lower classes.

Country-specific characteristics that have affected the intensity of the pivotal interaction between the rate of technological progress and the composition of the entrepreneurial traits within the population have generated variations in the transition from stagnation to growth and contributed to the disparity in income per capita across countries. Variations in institutional and cultural characteristics across societies affected the evolutionary process, stimulating the pace of the transition from stagnation to growth (Acemoglu et al. [1]). In particular: (a) The level of protection of intellectual property rights had an ambiguous effect on entrepreneurial activities, reflecting the trade-off between the positive effect of intellectual property rights on the incentive to innovate and its adverse effect on the proliferation of existing knowledge. (b) The stock of knowledge in a society and its rate of creation and diffusion created a platform on which faster technological innovations can emerge. (c) The composition of cultural and religious groups in a society and their attitude toward knowledge creation and diffusion affected the incentives to innovate. (d) The composition of interest groups in society generated incentives to block or promote technological innovation.

\section{7: Appendix}

\section{Proof of Lemma 1}

As follows from (10) and (11) $n^{2}\left(y_{t}\right)>1$ for all $y_{t} \geq \gamma / \tau$ if $n^{2}(\gamma / \tau)>1$ and therefore if [1$(\tau / \gamma)] / \tau>1$, which is satisfied since $\tau<1 / 2$ and $\gamma>1$.

\section{Proof of Lemma 3}

As follows directly from (18), $\varphi\left(0, y_{t}\right)=0$ and $\varphi\left(1, y_{t}\right)=1$ for $y_{t}<\gamma / \tau$. Differentiating (19),

$$
\phi_{\beta}\left(\beta_{t}, y_{t}\right)=\frac{n_{t}^{1} n_{t}^{2}}{\left[\beta_{t} n_{t}^{1}+\left(1-\beta_{t}\right) n_{t}^{2}\right]^{2}}>0
$$

and as follows from Corollary 1

$$
\phi_{\beta \beta}\left(\beta_{t}, y_{t}\right)=\frac{2 n_{t}^{1} n_{t}^{2}\left(n_{t}^{1}-n_{t}^{2}\right)}{\left[\beta_{t} n_{t}^{1}+\left(1-\beta_{t}\right) n_{t}^{2}\right]^{3}}\left\{\begin{array}{ccc}
<0 & \text { if } & 0<y_{t}<\gamma / \tau \\
>0 & \text { if } & y_{t}>\gamma / \tau
\end{array} .\right.
$$




\section{Proof of Lemma 5}

1. As follows from Lemma 1 and Corollary 1

$$
n^{1}(\gamma / \tau)>n^{2}(\gamma / \tau)>1 . \quad(40)
$$

Hence, the average level of fertility is at the replacement level only if:

$$
n^{R}\left(\beta_{t}\right)<\gamma / \tau \quad \forall \beta_{t} \in[0, \tau] .
$$

Furthermore, since $n^{1}\left(y_{t}\right)=1 / \tau$ for all $y_{t} \leq \gamma / \tau$, it follows that if the fraction of individuals type 1 in the population is equal to $\tau$, their fertility is such that the population as a whole have replacement fertility only if the fertility of individuals of type 2 is equal to zero. noting (43),

$$
y^{R}(\tau)=\tilde{y}, \quad(42)
$$

where $n^{2}(\tilde{y})=0$.

As follows from (28) there exists a function $\Omega\left(\beta_{t}, y_{t}^{R}\right)$ such that:

$$
\Omega\left(\beta_{t}, y_{t}^{R}\right)=\beta_{t} n^{1}\left(y_{t}^{R}\right)+\left(1-\beta_{t}\right) n^{2}\left(y_{t}^{R}\right)-1 \equiv 0 .
$$

Hence,

$$
\partial \Omega\left(\beta_{t}, y_{t}^{R}\right) / \partial y_{t}^{R}=\beta_{t} \frac{\partial n^{1}\left(y_{t}^{R}\right)}{\partial y_{t}^{R}}+\left(1-\beta_{t}\right) \frac{\partial n^{2}\left(y_{t}^{R}\right)}{\partial y_{t}^{R}}>0 .
$$

Thus, it follows from the Implicit Function Theorem, that there exists a continuous single-valued function, $y^{R}\left(\beta_{t}\right)$, such that:

$$
\left(\beta_{t}, y^{R}\left(\beta_{t}\right)\right) \in y y^{R} \quad \forall \beta_{t} \in[0, \tau] .
$$

2. As follows from from (43)

$$
\left.\frac{\partial y^{R}\left(\beta_{t}\right)}{\partial \beta_{t}}\right|_{y y^{R}}=-\frac{\partial \Omega\left(\beta_{t}, y_{t}^{R}\right) / \partial \beta_{t}^{R}}{\partial \Omega\left(\beta_{t}, y_{t}^{R}\right) / \partial y_{t}^{R}}=-\frac{n^{1}\left(y_{t}^{R}\right)-n^{2}\left(y_{t}^{R}\right)}{\beta_{t} \frac{\partial n^{1}\left(y_{t}^{R}\right)}{\partial y_{t}^{R}}+\left(1-\beta_{t}\right) \frac{\partial n^{2}\left(y_{t}^{R}\right)}{\partial y_{t}^{R}}}
$$

Hence, since $y_{t}^{R}<\gamma / \tau$, it follows from Corollary 1 that $n^{1}\left(y_{t}^{R}\right)-n^{2}\left(y_{t}^{R}\right)>0$, and therefore, noting (44),

$$
\left.\frac{\partial y^{R}\left(\beta_{t}\right)}{\partial \beta_{t}}\right|_{y y^{R}}<0 \quad \forall \beta_{t} \in[0, \tau] .
$$


3. Noting (11) fertility is positively affected by output per worker, and thus it follows from (28) that for any $\beta_{t} \in[0, \tau]$ :

$$
\beta_{t} n^{1}\left(y_{t}^{R}\right)+\left(1-\beta_{t}\right) n^{2}\left(y_{t}^{R}\right) \leqq 1 \forall y_{t} \geqq y_{t}^{R}\left(\beta_{t}\right)
$$

\section{Proof of Lemma 6}

1. As established in (30), $y_{t+1}-y_{t}=0$ if and only if:

$$
1+g\left(\beta_{t}, y_{t}\right)=\left[\beta_{t} n^{1}\left(y_{t}\right)+\left(1-\beta_{t}\right) n^{2}\left(y_{t}\right)\right]
$$

Hence since $\left[\beta_{t} n^{1}\left(y_{t}^{R}\right)+\left(1-\beta_{t}\right) n^{2}\left(y_{t}^{R}\right)\right]=1$, and $g\left(\beta_{t}, y_{t}^{R}\right)=0$ it follows that $\left(\beta_{t}, y^{R}\left(\beta_{t}\right)\right) \in y y \forall \beta_{t} \in[0, \tau]$.

2. As established in (29), $y_{t+1}-y_{t}=0$ if and only if $\psi\left(\beta_{t}, y_{t}\right)-y_{t}=0$. As follows from (30),

$$
\left.\frac{\partial y_{t}}{\partial \beta_{t}}\right|_{y_{t+1}-y_{t}=0}=\frac{\left[n^{1}\left(y_{t}\right)-n^{2}\left(y_{t}\right)\right]-g_{\beta}\left(\beta_{t}, y_{t}\right)}{g_{y}\left(\beta_{t}, y_{t}\right)-\left[\beta_{t} \frac{\partial n^{1}\left(y_{t}\right)}{\partial y_{t}}+\left(1-\beta_{t}\right) \frac{\partial n^{2}\left(y_{t}\right)}{\partial y_{t}}\right]} .
$$

Hence, it follows from (A2) that along the $y y$ locus, that denominator does not vanish, and there exists a decreasing continuous, single-valued function $y\left(\beta_{t}\right) \in$ $\left(y^{R}\left(\beta_{t}\right), \gamma / \tau\right)$ such that:

$$
\left(\beta_{t}, y\left(\beta_{t}\right)\right) \in y y
$$

where $\forall \beta_{t} \in[0, \hat{\beta})$

$$
\left.\frac{\partial y_{t}}{\partial \beta_{t}}\right|_{y_{t+1}-y_{t}=0}<0
$$

Moreover, as follows from the Intermediate Value Theorem, noting (A2),

$\lim _{\beta_{t} \rightarrow \hat{\beta}} y\left(\beta_{t}\right)=y^{R}(\hat{\beta}) y(0) \in(\breve{y}, \gamma / \tau)$, and $\hat{\beta} \in[\breve{\beta}, \tau]$.

3. As established in Lemma $1, \beta_{t} n^{1}\left(y_{t}\right)+\left(1-\beta_{t}\right) n^{2}\left(y_{t}\right)<1$ iff

$\beta_{t} n^{1}\left(y_{t}\right)+\left(1-\beta_{t}\right) n^{2}\left(y_{t}\right)<1$ iff $\quad y_{t}<y_{t}^{R}\left(\beta_{t}\right)$. Hence since $g\left(\beta_{t}, y_{t}\right)=0$ for all $y_{t} \leq y_{t}^{R}$, it follows that

$$
y_{t+1}-y_{t}>0 \quad \text { if } \quad 0<y_{t} \leq y_{t}^{R}
$$


As follows from Assumption (A2), $y_{t+1}-y_{t}<0$ if and only if $y^{R}\left(\beta_{t}\right)<y_{t}<y\left(\beta_{t}\right)$ and $\beta_{t} \in[0, \hat{\beta})$.

\section{References}

[1]. Acemoglu, D.; D.; Johnson, S.; Robinson, JA. Institutions as a Fundamental Cause of Long-Run Growth. In: Aghion, P.; Durlauf, SN., editors. Handbook of Economic Growth. Elsevier NorthHolland; Amsterdam, The Netherlands: 2005. p. 109-139.

[2]. Aghion P, Howitt P. A model of growth through creative destruction. Econometrica. 1992; 60:323-351.

[3]. Bertocchi G. The law of primogeniture and the transition from landed aristocracy to industrial democracy. J. of Econ. Growth. 2006; 11:41-68.

[4]. Bisin A, Verdier T. Beyond the melting pot: cultural transmission, marriage, and the evolution of ethnic and religious traits. Quart. J. of Econ. 2000; 115:955-988.

[5]. Borghans, J.; Borghans, L.; ter Weel, B. Cross-country evidence from the major histocompatibility complex. Department of Economics, Maastricht University; 2005. Is there a link between economic outcomes and genetic evolution?. Working Paper

[6]. Bowles S. Endogenous preferences: the cultural consequences of markets and other eco nomic institutions. J. of Econ. Lit. 1998; 36:75-111.

[7]. Boyd, R.; Richerson, PJ. Culture and the Evolutionary Process. University of Chicago Press; Chicago, IL: 1985.

[8]. Cavalli-Sforza, LL.; Feldman, MW. Cultural Transmission and Evolution: A Quantita tive Approach. Princeton University Press; Princeton, NJ: 1981.

[9]. Cloninger CR. A systematic method for clinical description and classification of person ality variants: a proposal. Arch. of Gen. Psych. 1987; 44:573-588.

[10]. Ding Y-C, Chi H-C, Grady DL, Morishima A, Kidd JR, Kidd KK, Pamela Flodman MAS, Schuck S, Swanson JM, Zhang Y-P, Moyzis RK. Evidence of positive selection acting at the human dopamine receptor D4 gene locus. Proc. of the Nat. Ac. of Sci. of the Uni. Sta. of Amer. 2002; 99:309-314.

[11]. Doepke M, Zilibotti F. Social Class and the Spirit of Capitalism. J. of the Eur. Econ. Assoc. 2005; 3:516-524.

[12]. Doepke M, Zilibotti F. Occupational choice and the spirit of capitalism. Quart. J. of Econ. 2008; 2:747-793.

[13]. Dohmen T, Falk A, Huffman D, Sunde U, Schupp J, Wagner GG. Individual risk attitudes: new evidence from a large, representative, experimentally validated survey. 2005 Discussion Paper No. 1730, IZA.

[14]. Durham WH. Interaction of genetic and cultural evolution: models and examples. Hu man Ecol. 1982; 10:289-323.

[15]. Finkelman E, Finkelstein I. Introducing socioeconomic characteristics into production analysis under risk. Agr. Econ. 1996; 13:149-161.

[16]. Galor, O. From stagnation to growth: unified growth theory. In: Aghion, P.; Durlauf, S., editors. Handbook of Economic Growth. Elsevier; Holland: 2005.

[17]. Galor O, Moav O. Natural selection and the origin of economic growth. Quart. J. of Econ. 2002; 117:1133-1191.

[18]. Galor, O.; Moav, O. The neolithic revolution and contemporary variations in life ex pectancy. Department of Economics, Brown University; 2007. Working Paper

[19]. Galor O, Weil DN. From Malthusian stagnation to modern growth. Amer. Econ. Rev. 1999; 89:150-154.

[20]. Galor O, Weil DN. Population, technology, and growth: from Malthusian stagnation to the demographic transition and beyond. Amer. Econ. Rev. 2000; 90:806-828.

[21]. Hansen GD, Prescott EC. Malthus to Solow. Amer. Econ. Rev. 2002; 92:1205-1217. 
[22]. Harris JA, Vernon PA, Boomsma DI. The heritability of testosterone: a study of Dutch adolescent twins and their parents. Behav. Genet. 1998; 28:165-171. [PubMed: 9670592]

[23]. Hayek, FA. Individualism and Economic Order. University of Chicago Press; Chicago, IL: 1948.

[24]. Kirzner, I. Competition and Entrepreneurship. University of Chicago Press; IL, Chicago: 1973.

[25]. Kohler H-P, Rodgers JL, Christensen K. Is fertility behavior in our genes? Findings from a Danish twin study. Pop. and Dev. Rev. 1999; 25:253-288.

[26]. Kose S. A psychobiological model of temperament and character. TCI Yeni Symposium. 2003; 41:86-97.

[27]. Lagerlöf N-P. Long-run trends in human body mass. Macroec. Dyn. 2007; 11:367-387.

[28]. Livingstone FB. Anthropological implications of sickle cell distribution in west Africa. Amer. Anthropol. 1958; 60:533-562.

[29]. Lucas, R. The Industrial Revolution: Past and Future. Harvard University Press; Cam bridge, MA: 2002.

[30]. Meikle A, Stringham J, Bishop D, West D. Quantitating genetic and nongenetic factors influencing androgen production and clearance rates in men. J. of Clinic. Endocrin. and Metab. 1988; 67:104-109.

[31]. Mekel-Bobrov N, Gilbert SL, Evans PD, Vallender EJ, Anderson JR, Hudson RR, Tishkoff SA, Lahn BT. Ongoing adaptive evolution of ASPM, a brain size determinant in Homo sapiens. Science. 2005; 309:1720-1722.

[32]. Miyata S. Household's risk attitudes in Indonesian villages. Appl. Econ. 2003; 35:573-583.

[33]. Nielsen R, Bustamante C, Clark AG, Glanowski S, et al. A scan for positively selected genes in the genomes of humans and chimpanzees. PLos Biology. 2005; 3:e170. [PubMed: 15869325]

[34]. Ofek, H. Second Nature: Economic Origin of Human Evolution. Cambridge University Press; Cambridge, UK: 2001.

[35]. Palacios-Huerta I, Santos TJ. A theory of markets, institutions, and endogenous pref erences. J. of Pub. Econ. 2004; 88:601-627.

[36]. Rodgers JL, Kohler H-P, Kyvik KO, Christensen K. Behavior genetic modeling of human fertility: findings from a contemporary Danish twin study. Demography. 2001; 38:29-42. [PubMed: 11227843]

[37]. Saint-Paul G. On market forces and human evolution. J. of Theoret. Biol. 2007; 247:397-412. [PubMed: 17467742]

[38]. Schumpeter, JA. The Theory of Economic Development. Harvard University Press; Cam bridge, MA: 1934.

[39]. Spolaore E, Wacziarg R. The diffusion of development. Quart. J. of Econ. 2009; 124:469-529.

[40]. Voight BF, Kudaravalli S, Wen X, Pritchard JK. A map of recent positive selection in the human genome. PLos Biology. 2006; 4:e72. [PubMed: 16494531]

[41]. Weibull, J. Evolutionary Game Theory. MIT Press; Cambridge, MA: 1995.

[42]. Weibull J, Salomonsson M. Natural selection and social preferences. J. of Theoret. Biol. 2006; 239:79-92. [PubMed: 16174522]

[43]. Welch Y, Bernardo A. On the evolution of overconfidence and entrepreneurs. J. of Econ. and Manag. Strat. 2001; 10:301-330.

[44]. White RE, Thornhill S, Hampson E. Entrepreneurs and evolutionary biology: the Re lationship between testosterone and new venture creation. Organiz. Behav. and Human Decision Processes. 2006; 100:21-34.

[45]. Wiesenfeld SL. Sickle cell trait in human biological and cultural evolution. Science. 1967; 157:1135-1140. 


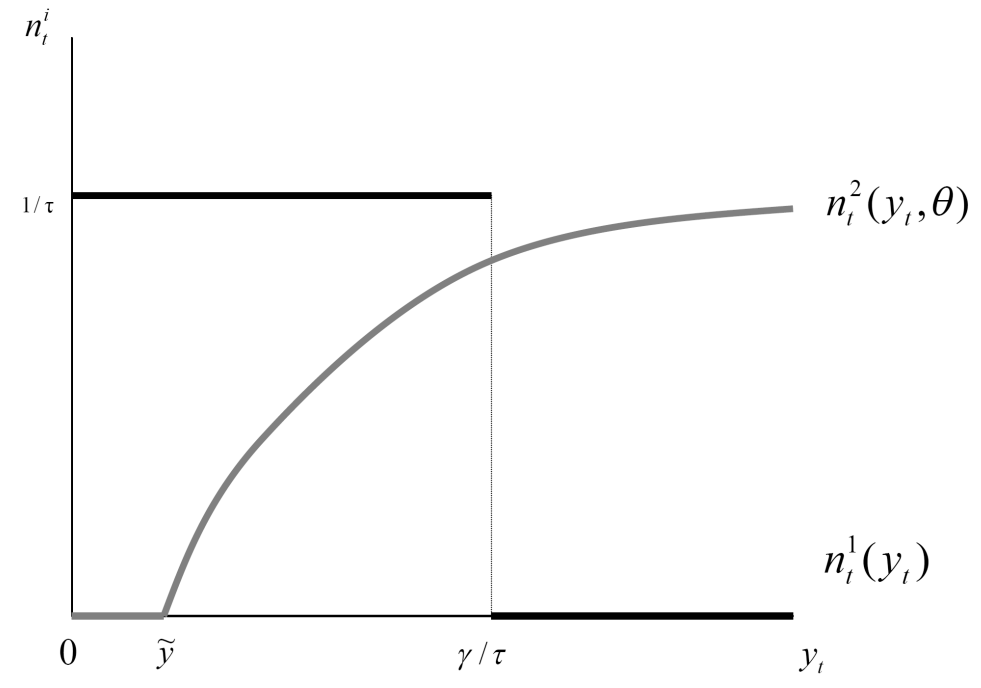

Figure 1.

Reversal in the Evolutionary Advantage in the Process of Development. 


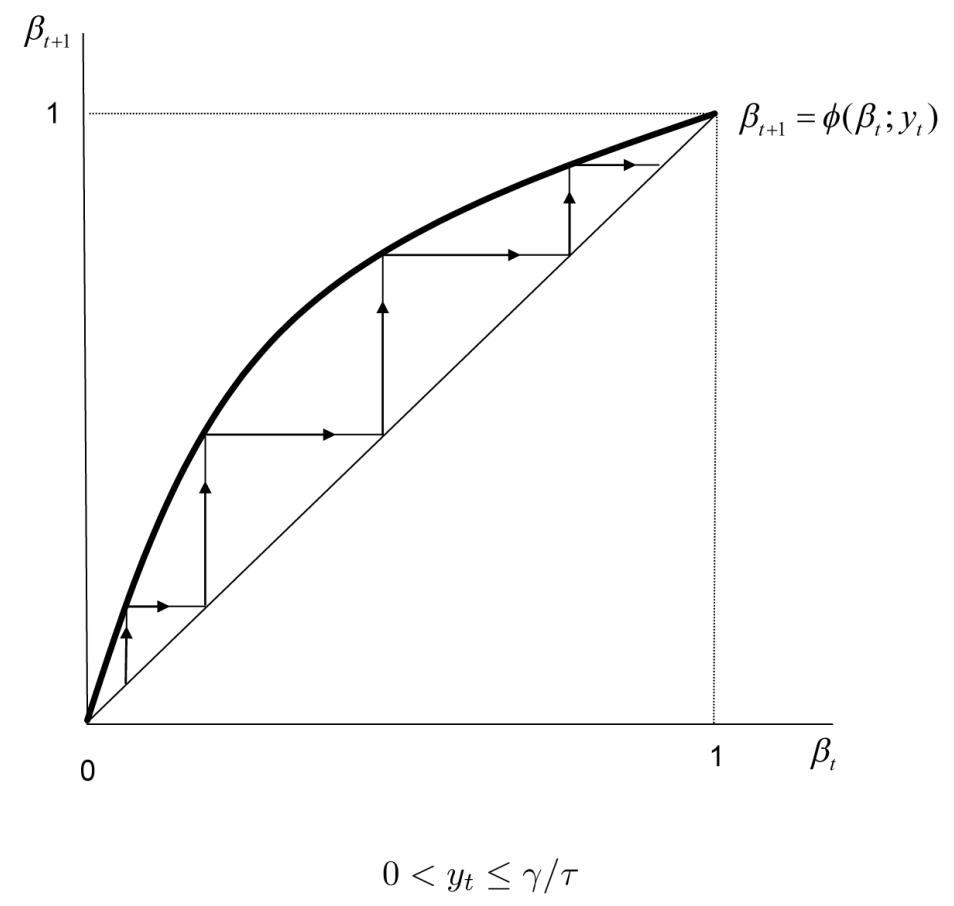

Figure 2.

The Evolution of the Proportion of Risk-Neutral Individuals, $\beta_{t}$. 


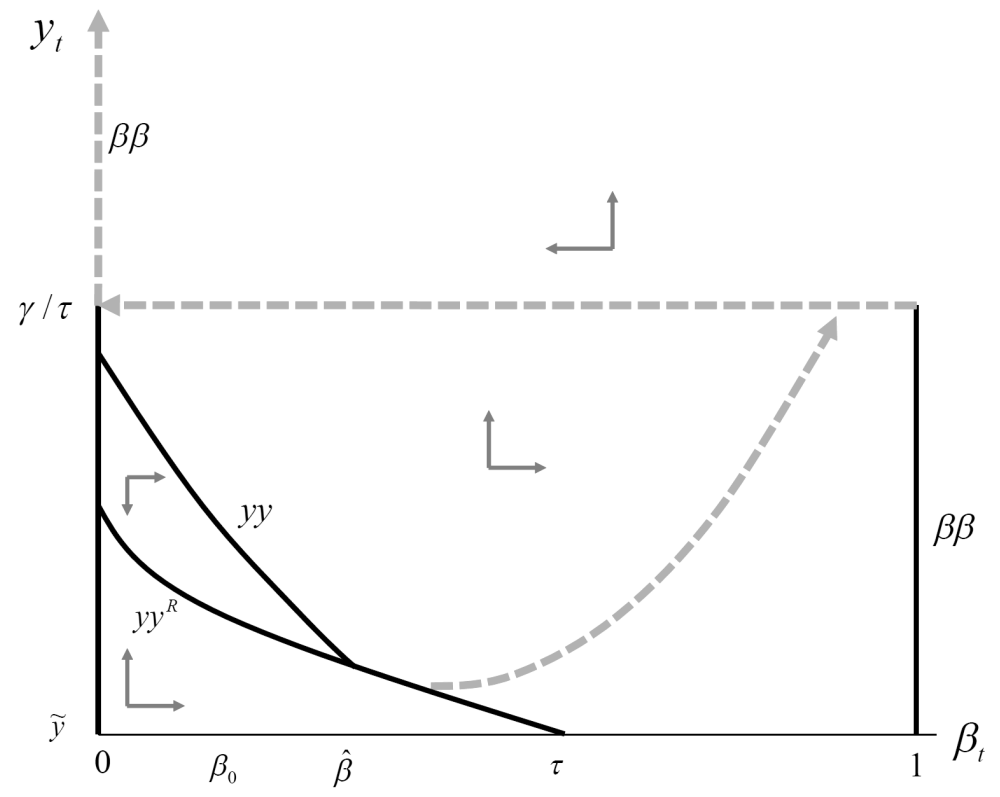

Figure 3.

The Evolution of Entrepreneurial Spirit and the Process of Development. 